\title{
O PAPEL DAS NOVAS TECNOLOGIAS DA COMUNICAÇÃO E DA EDUCAÇÃO A DISTÂNCIA PARA RESPONDER À CRISE GLOBAL NA OFERTA E FORMAÇÃO DE PROFESSORES: UMA ANÁLISE DA EXPERIÊNCIA DE PESQUISA E DESENVOLVIMENTO*
}

\author{
BOB MoON
}

RESUMO: Este artigo enfoca o maior problema que ameaça todas as sociedades: atrair, reter e formar professores, particularmente em lugares onde os sistemas escolares estão se expandindo rapidamente. Examina as características da "crise dos professores" em relação a dados mundiais, dando uma atenção particular a lugares-chave na África e na Ásia. Esse contexto constitui o quadro de análise de um leque de pesquisas e programas de desenvolvimento que buscam usar as novas tecnologias da comunicação e da educação a distância para enfrentar a escala do desafio colocado.

Palavras-chave: Novas tecnologias da comunicação. Educação a distância. Oferta de professor. Formação de professor. Recursos educacionais abertos.

\footnotetext{
* Partes deste artigo foram extraídas de relatórios da UNESCO, preparados pelo autor para o Comitê de Peritos sobre a aplicação de recomendações a respeito do pessoal docente e para um encontro da UNESCO sobre os países E9 (os nove países em desenvolvimento com as maiores populações mundiais). Disponível em: <http://unesdoc.unesco.org/images/ 0015/001516/151685E.pdf>.

Tradução de Alain François, com revisão técnica de Antonio Zuin.

** Professor da Faculdade de Educação e Estudos da Linguagem, Departamento de Educação, The Open University (Reino Unido).E-mail: r.e.moon@open.ac.uk
} 
O papel das novas tecnologias da comunicação e da educação a distância...

THE ROLE OF NEW COMMUNICATION TECHNOLOGIES AND DISTANCE EDUCATION IN RESPONDING TO THE GLOBAL CRISIS IN TEACHER SUPPLY AND TRAINING: AN ANALYSIS OF THE RESEARCH AND DEVELOPMENT EXPERIENCE

ABSTRACT: This paper explores the major problem facing all societies to attract, retain and train teachers, particularly where school systems are expanding rapidly. The characteristics of the 'teacher crisis' will be examined by reference to global evidence, giving particular attention to key locations in Africa and Asia. This context then provides the framework for analysing a range of research and development programmes that seek to harness new communication technologies and distance education to meet the scale of the challenge posed.

Key words: New communication technologies. Distance education. Teacher supply. Teacher training. Open educational resources.

\section{Introdução}

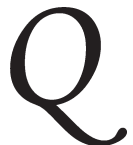

uem não se lembra de um bom professor? Mesmo assim, ele pode ter várias aparências. De fato, professores podem ser inspiradores, conscienciosos, atenciosos e, muitas vezes, dedicados. Uns raros têm a sorte de ter todas essas características e mais ainda. Em todas as sociedades, o professor é a figura que inspira mitos, histórias, memórias. Fortes emoções circundam o papel do professor: confiança, deferência, amor e, por vezes, medo. Nas comunidades rurais, o professor primário do vilarejo, junto com um padre, um prefeito e um ancião, proporcionavam tradicionalmente uma orientação moral que oferecia uma mediação entre os Estados recém surgidos e as comunidades que tentavam manter juntas.

Entretanto, neste começo do século XXI, essas idéias folclóricas sobre "o professor" são postas em xeque. Em muitas partes do mundo, a vocação de ensino apresenta os traços de uma crise. Quase todos os países estão lutando para contratar professores suficientes. Em algumas regiōes (na África subsaariana, por exemplo), os problemas de contratação, retenção e formação de professores constituem um problema agudo. Este artigo examinará a forma que essa crise está tomando e, mais particularmente, os desafios organizacionais e logísticos associados 
ao fornecimento de educação e formação suficientes para os milhões de novos professores necessários para expandir os sistemas educacionais. Uma atenção especial será dada aos contextos do mundo em desenvolvimento, onde esforços internacionais expressivos estão sendo feitos para superar o que se poderia chamar de o maior desafio educacional mundial. Este artigo também examinará a experiência de pesquisa e desenvolvimento de uma série de programas de aprendizados abertos e a distância, com uma menção especial para o papel emergente das novas tecnologias da informação e da comunicação, inclusive os "recursos educacionais abertos" (Open Educational Resources).

\section{O desafio de contratar e reter professores}

Atrair pessoas jovens ou maduras para o ensino é um enorme desafio. Em muitos países do mundo a oferta não atende à demanda. A situação na África subsaariana já foi descrita como uma crise (Dladla \& Moon, 2006) e pelo menos um país, Burkina Faso, declarou oficialmente que a oferta de professores constituía uma crise "nacional". No primeiro encontro de coordenadores nacionais para a Teacher Training Initiative for Sub-Saharan Africa (Iniciativa de Formação de Professores para a África subsaariana) da UNESCO (7-9 de março de 2006, Dakar, Senegal), o representante da República Unida da Tanzânia revelou que o ensino do seu país estava em crise (Mhando, 2006). Mesmo em lugares onde há bons progressos rumo a uma taxa de escolarização de $100 \%$, problemas de qualidade começam a surgir. A Índia, por exemplo, alcançou uma taxa de escolarização de mais de $93 \%$ no ensino fundamental (entre 6 e 14 anos) em torno de 2005, mas um estudo com mais de 330 mil crianças em 9.500 aldeias mostrou que 35\% das crianças de nível I não conseguiam ler um pequeno parágrafo com frases curtas e $40 \%$ das crianças no nível V não sabiam ler um texto de nível II (uma simples história). Por outro lado, no ensino fundamental federal, $50 \%$ das crianças de nível II a V não conseguiam resolver um problema de subtração envolvendo dezenas e, em nível VI a VIII dessas mesmas escolas, $40 \%$ não sabiam resolver um simples problema de divisão (centenas por unidade) (Gandhi Kingdon, 2007).

Contudo, esses problemas não se limitam aos países em desenvolvimento. $\mathrm{Na}$ Califórnia, milhares de professores leigos estão trabalhando no sistema escolar fundamental. Um esquema especial de formação 
O papel das novas tecnologias da comunicação e da educação a distância...

centrada na escola teve de ser desenvolvido pela Universidade Estadual da Califórnia, com novos fundos estaduais. Na Europa, a falta de professores secundários especializados em matemática e ciência, por exemplo, é aguda. Para entender a escala do problema que as sociedades enfrentam é interessante examinar mais em detalhe duas regiōes na África e na Ásia.

\section{África subsaariana}

Internacionalmente, quase todos os países assinaram os compromissos da UNESCO e da ONU de atingir a ensino fundamental universal para todas as crianças até 2015. Entretanto, poucas declaraçóes, inclusive a do Fórum Mundial de Dakar, em 2000, ou os Objetivos de Desenvolvimento do Milênio, reconhecem explicitamente a importância dos professores para alcançar suas metas. Isso foi ressaltado no documento de posicionamento (position paper) produzido para a recémlançada Iniciativa de Formação de Professores para a África subsaariana da UNESCO.

As pessoas estão, finalmente, começando a escutar aqueles que viam na falta de professores qualificados um dos maiores impedimentos ao desenvolvimento nacional e as autoridades nacionais e internacionais estão começando a perceber que o cumprimento dos Objetivos de Desenvolvimento do Milênio e da Educação para Todos depende da formação de profissionais capazes de um esforço de longo prazo para promover efetivamente a educação, em particular através da formação de professores e de pessoais de diretoria no sistema educacional. (p. 2)

O Relatório da Comissão para a África (2005) fez do investimento na formação de professor a sua principal recomendação, quando disse: “(...) o esforço para conseguir a Educação para Todos nunca terá a menor chance de sucesso sem um investimento substancial em contratação, formação, retenção e desenvolvimento profissional de professores" (p. 186).

Entretanto, as necessidades são tamanhas que chegam a ser desanimadoras (ver Dembele \& Miaro-II, 2003). Relatórios sucessivos têm ressaltado o grande número de professores leigos nas escolas e a dificuldade para atrair novos candidatos. Um levantamento da UNESCO (2000) em 11 países da África oriental e austral indicou que um terço 
dos professores primários não tinha formação. Lewin (2002) mostrou que o déficit de professores formados aumentou e vai se tornar maior ainda, caso a expansão necessária para alcançar as metas da Educação para Todos continuar.

Dois fatores parecem mais particularmente ter um impacto sobre a profissão docente na maioria dos países da África subsaariana. Primeiro, a queda dos salários em relação a outras profissōes comparáveis, que foi bem documentada (Colclough et al., 2003), sendo que as economias do conhecimento emergentes oferecem oportunidades alternativas de emprego para aqueles que costumavam formar o viveiro tradicional de professores primários. Segundo, o HIV/AIDS está tendo um impacto sobre a força de trabalho docente existente e potencial. A UNICEF (2000) estimou que, por ano, quase um milhão de crianças perde seu professor por causa do HIV/AIDS.

Um relatório sul-africano recente (Education in Labour Relations Council [Conselho da Educação nas Relações de Trabalho], 2005) conseguiu chamar a atenção para seus resultados graças a uma manchete alarmante nas mídias: "Um professor morre a cada duas horas". No Quênia, o número de professores que morrem de AIDS todo ano supera o de professores diplomados pelas instituiçôes de formação de professor (Rémy, 2002). Na Zâmbia, o HIV/AIDS tira a vida de 2 mil professores por ano, número também superior ao dos professores formados pelas faculdades (McGreal, 2005). Um estudo na Namíbia (Melaney, 2000) mostrou que, se a oferta de novos professores permanecer em 1 mil, o déficit de professores devido ao impacto do HIV/AIDS será em torno de 7.161 até 2010. Como em muitas partes da África, essas estatísticas não refletem as expressivas disparidades regionais internas. $\mathrm{Na}$ Namíbia, por exemplo, taxas particularmente altas de infecção existem nas regiôes norte de Ondangwa oriental e Ondangwa ocidental. Previsivelmente, estas são áreas com o maior número de alunos por sala de aula, pois $80 \%$ da população total do país moram nelas (idem, ibid.). Embora a questão do impacto do HIV/AIDS sobre os professores tenha provocado algumas controvérsias (ver Bennett, 2005), independentemente da magnitude do seu impacto, está claro que essa pandemia está tendo uma influência significativa sobre as condiçôes de trabalho dos professores (ver Boler, 2003).

Entre as pressōes exercidas sobre os professores da África subsaariana devemos também incluir os problemas de corrupção nos serviços 
O papel das novas tecnologias da comunicação e da educação a distância...

públicos. Existem muito poucos dados especificamente a respeito dos professores, mas, onde existem, apontam maiores pressões financeiras sobre as vidas destes. No Quênia, por exemplo, Transparency International (2006) mostrou que o suborno em torno das lotaçóes e transferências de professores reina absoluto.

Nesse contexto desafiador, a palavra "crise" está começando a ser usada. Em Burkina Faso, a falta de professores foi declarada urgência nacional e pessoas estão sendo contratadas em todos os setores públicos para preencher as vagas imediatamente (Commission for Africa Report [Relatório da Comissão para a África], 2005). Em certos países (como o Sudão, por exemplo), um ano ou dois de ensino constituem, hoje em dia, uma alternativa para o serviço militar obrigatório.

É difícil estabelecer estimativas gerais sobre o número de professores adicionais que serão necessários na África subsaariana até 2015 . Do mesmo modo, é difícil estabelecer estimativas do número total de professores leigos (a começar pelo fato de que cada país usa uma definição diferente do que vem a ser um professor "qualificado"). A Global Campaign for Education (Campanha Mundial para a Educação [2006]), que trabalhou a partir de dados da UNESCO, estimou que 14 a 22,5 milhões de professores adicionais serão necessários no mundo para alcançar a Educação para Todos (pois esse número depende das razões alunos-professor consideradas) e muito mais professores em função precisam urgentemente de educação e formação. Por este motivo, o Education for All Monitoring Report (Relatório de Supervisão da Educação para Todos [UNESCO, 2005]) ressaltava aos professores:

Alcançar os objetivos do Ensino Fundamental para Todos exige professores mais numerosos e melhor formados. Os países que conseguiram altos padrões de aprendizado investiram pesadamente na profissão docente. Entretanto, em muitos países, os salários dos professores, quando comparados aos de outras profissōes, caíram, nessas últimas duas décadas, e ficaram baixos demais para propiciar um nível de vida razoável. Os modelos de formação de professores deveriam ser reconsiderados, em muitos países, para reforçar a formação inicial e continuada centrada na escola, em vez de depender da formação inicial, tradicional e demorada, em instituições. (p. 3)

Além do mais, a África subsaariana sofre de dois problemas que ocorrem em outros lugares no mundo, mas não na mesma escala. O 
primeiro é a migração de professores. De fato, a Europa e a América do Norte estão contratando ativamente professores graduados de vários países africanos. Os melhores professores e os mais experimentados costumam ser os primeiros a se mudar, e os benefícios do investimento em formação são colhidos em outros lugares. Poucos dados consolidados existem sobre a migração de professores, mas, à medida que os custos de mobilidade estão caindo, ela parece constituir um problema crescente.

O segundo problema diz respeito aos milhões de professores que estão sendo contratados, mas na realidade são paraprofissionais. A Campanha Mundial para a Educação (2006) vê isso como uma conseqüência parcial das restrições financeiras:

$\mathrm{Na}$ África ocidental, o sistema educacional é cada vez mais um campo para "paraprofessores", com uma formação inicial de apenas alguns meses ou mesmo algumas semanas. Isto é um ataque direto contra a educação de qualidade à qual todos aspiram e têm direito. Muitas vezes, por causa da crise dos professores, a qualidade tornou-se refém da quantidade. Para responder ao aumento de matrículas, a tendência é contratar tantos professores quanto for possível, mesmo se não têm as qualificações necessárias. (p. 27)

Também é importante lembrar o grande número de alunos por sala de aula que muitos professores, treinados ou não, têm de enfrentar. Em países como o Mali, a Etiópia e o Moçambique, as razões alunosprofessor ultrapassam 55:1. No Botsuana, no Gana e na Namíbia, estão entre 25 e 34:1 e a República do Congo chega a 83:1 (UnesCO, 2008). Entretanto, o tamanho real das salas de aula pode ser muito maior, uma vez que as escolas rurais da maioria dos países costumam ser muito pequenas, o que não deixa de ter um impacto claro sobre as percentagens gerais. Do mesmo modo, o número total de professores leigos é difícil de estimar (a começar pelo fato de que cada país usa uma definição diferente do que vem a ser um professor "qualificado").

\section{Sul e Leste asiático}

Um estudo recente do Instituto de Estatísticas da UNESCO (2006) indica que os países do Sul e do Leste asiático enfrentam uma escassez de professores ameaçadora no seu caminho rumo ao ensino fundamental 
O papel das novas tecnologias da comunicação e da educação a distância...

para todas as crianças até 2015. Para alcançar seus objetivos de expansão e substituir os professores existentes, essas regiōes vão precisar de mais 3,5 milhões de professores até lá. A tabela abaixo mostra isso em relação ao ensino fundamental:

\section{Tabela 1}

Número e fluxos de professores primários e professores adicionais necessários para alcançar o Ensino Fundamental para Todos até 2015 (em milhares)

\begin{tabular}{|c|c|c|c|c|c|}
\hline \multirow[b]{2}{*}{ País ou território } & \multicolumn{3}{|c|}{ Número de professores primários } & \multicolumn{2}{|c|}{$\begin{array}{l}\text { Fluxos de professores primários, } \\
\qquad 2004-2015\end{array}$} \\
\hline & 2004 & 2015 & Diferença & $\begin{array}{l}\text { Professores } \\
\text { para preencher } \\
\text { vagas em razão } \\
\text { do desgaste } \\
(6.5 \%)\end{array}$ & $\begin{array}{l}\text { Número total } \\
\text { de professores } \\
\text { necessários } \\
\text { para o Ensino } \\
\text { Fundamental } \\
\text { para Todos e o } \\
\text { desgaste }\end{array}$ \\
\hline $\begin{array}{l}\text { Afeganistão, República } \\
\text { Islâmica do }\end{array}$ & 68 & 172 & 103,8 & 76,7 & 180,5 \\
\hline Bangladesh & 327 & 453 & 125,7 & 272,2 & 397,9 \\
\hline Índia & $3.038^{-1}$ & 2.988 & $-49,8$ & $2.108,8$ & $2.108,8$ \\
\hline Irã, República Islâmica do & 365 & 332 & $-33,6$ & 216,4 & 216,4 \\
\hline Nepal & 112 & 113 & 0,7 & 80,6 & 81,2 \\
\hline Paquistão & 432 & 606 & 174,2 & 362,2 & 536,4 \\
\hline Sri Lanka & $73^{* *}-1$ & 68 & $-4,9$ & 45,7 & 45,7 \\
\hline
\end{tabular}

Notas: O número de professores projetado para 2015 baseia-se nas estimativas da população com idade para freqüentar o ensino fundamental em 2015 mais $10 \%$ ou metade das taxas atuais de repetência divididas pela razão alunos-professores de 40:1 (ou a razão atual, se estiver mais baixa).

${ }^{-1}$ Esses dados se referem a 2003. ${ }^{* *}$ Estimativas do UIS (Instituto de Estatísticas da UNESCO)

Alguns países enfrentam desafios particulares. No Afeganistão, a população em idade escolar crescerá $34 \%$ na próxima década, acarretando uma ampla demanda por professores (as atuais razōes alunos/professor são de 65:1). No Paquistão, o número de alunos 
deveria aumentar em 10\% até 2015, mas, hoje em dia, 34\% das crianças com idade para freqüentar o ensino fundamental estão fora da escola.

MacDonald (1999) apontou a falta de dados (e a sua natureza) sobre professores na região. Definir níveis de qualificação, por exemplo, parece particularmente complicado. Entretanto, mesmo com um nível de qualificação baixo, muitos professores não satisfazem as exigências nacionais. No Nepal, 25\% dos professores não são diplomados. Esse número é de 30\% nas Maldivas e de 18\% em Bangladesh. Nilsson (2003) ressalta os baixos números de professoras em muitos países da região e o seu impacto sobre as matrículas de meninas nas escolas. Como na África subsaariana, o HIV/AIDs também tem um impacto sobre a força de trabalho docente, embora não existam muitos dados detalhados a respeito. Contudo, suas conseqüências para os professores levantam questões de um tipo novo e único em termos de políticas para professores. Como enfatiza Nilsson (op. cit., p. 148):

A maioria das pessoas infectadas pelo HIV continua clinicamente saudável por vários anos depois de sua infecção, mas seu sistema imunológico vai se deteriorando gradualmente, acarretando uma alternância de períodos de doença e de saúde relativamente boa. Os professores infectados costumam conseguir ensinar durante os períodos de boa saúde, mas faltam durante os períodos de doença, que tendem a ser mais freqüentes e durar mais à medida que a doença vai avançando. Segundo estimativas do Banco Mundial, um professor infectado consegue trabalhar aproximadamente 260 dias antes de morrer de AIDS. Por outro lado, o tempo gasto para cuidar de parentes doentes e ir a funerais também influi sobre a presença dos professores nas escolas.

Em resumo, na maior parte do mundo, o problema da oferta de professores cresceu nessas últimas décadas. Ele se manifesta de modo diferente segundo os lugares e, em alguns contextos, chega a constituir uma crise importantíssima. Contudo, existem, no problema geral da oferta, certas subquestões cuja interação é crucial para as políticas. Elas incluem:

- a retenção de professores qualificados, i.e., a taxa de rotatividade;

- o perfil etário dos professores; 
O papel das novas tecnologias da comunicação e da educação a distância...

- a especialização dos professores em matérias do ensino fundamental e médio;

- o equilíbrio, em termos de gênero, entre os professores das diferentes áreas;

- a migração dos professores entre diferentes países (mais precisamente na África austral).

\section{Criar as "condições políticas” para as mudanças}

Um número de estudos recentes examinou as tendências mundiais na educação dos professores. Moon e outros (2003) fizeram isso para a UNESCO na Europa. Morris e Williamson (2000) o fizeram para a região Ásia-Pacífico.

A primeira conclusão geral a respeito desses estudos é que quase todos mostram que a última década testemunhou um número sem precedente de ações governamentais legislativas, regulatórias, ou outras, dirigidas à educação dos professores. Apesar de suas formas diferentes, a impressão geral é de que mais atenção política foi dada à educação dos professores na década de 1990 do que nas centenas de anos de história que a precederam, e que a maior parte dessas ações enfocou a qualidade. Durante grande parte do fim do século passado, houve uma preocupação em criar estruturas institucionais que pudessem fornecer o grande número de professores exigido pela obrigatoriedade do ensino nas escolas primárias e secundárias. À medida que o fim do século se aproximava, expectativas cada vez maiores foram criadas a respeito do que os professores deveriam saber e ser capazes de fazer no momento de sua qualificação.

A segunda é que quase todas essas atividades enfocaram a formação inicial. Na maioria dos países, a formação continuada, cada vez mais chamada de desenvolvimento profissional continuado (DPC), desperta muito pouco interesse político e costuma ser fornecida de modo mal coordenado e com poucos recursos financeiros (Villegar-Reimer, 2001). Embora existam algumas exceções e novos modelos de organização sejam explorados, no geral, os estudos revelam várias preocupaçôes importantes em torno dessa questão.

Em muitos países, um dos maiores desafios a ser enfrentado pela educação dos professores é fornecer uma base política estável para o 
desenvolvimento. Após uma revisão de uma série de trabalhos de pesquisa bem documentados sobre a região, Lewin (2002) concluiu que as políticas para a educação dos professores são fragmentadas, incompletas e, via de regra, simplesmente subdesenvolvidas. Nesse contexto, alguns problemas-chave são freqüentemente ignorados. Seis são particularmente pertinentes para reestruturar as condições políticas em torno da educação dos professores.

O primeiro é que os recursos são alocados para cursos longos, de três ou quatro anos, os quais formam apenas uma minoria dos professores necessários. Em alguns contextos, portanto, enquanto essa minoria recebe um apoio considerável, um processo paralelo ocorre para contratar muito mais professores leigos no sistema escolar.

O segundo é que certos professores primários usam sua qualificação como um meio para encontrar outras formas de emprego ou para se formar para o ensino médio. Recursos importantes estão sendo alocados para "promover os professores primários", sem qualquer esperança de retorno em termos de uma melhor qualidade de ensino nas escolas. Esta é uma questão que afeta mais amplamente as políticas para os salários e os incentivos dos professores, mas seu impacto sobre a eficiência da educação e da formação pode ser imenso.

O terceiro, que decorre do anterior, é que o status dos professores, particularmente no ensino fundamental, é cada vez mais problemático. Os salários são claramente importantes (Colclough et al., 2003), mas algumas questōes mais sutis, associadas com a posição e o respeito na comunidade, são mais difíceis de se definir. Um relatório recente sobre a educação em comunidades rurais sul-africanas (Nelson Mandela Foundation, 2004) ressaltou as preocupações de pais, alunos e outros para com o compromisso e o status dos professores.

Em muitas comunidades, existe uma profunda fratura entre os professores e os responsáveis legais das crianças (...). As críticas aos professores incluem um conjunto complexo de questôes relacionadas à sua falta da qualificação, de conhecimento da matéria ensinada e de sentido de vocação. (p. 107)

O mesmo relatório identificou um quarto problema, área importante de preocupação, na forma e na natureza do currículo de educação dos professores, para quem tem acesso a ele. Percebeu um legado 
O papel das novas tecnologias da comunicação e da educação a distância...

de “(...) faculdades que proliferaram nessas terras e forneceram pouco mais do que uma repetição do programa de ensino médio embrulhada numa pedagogia autoritária” (p. 108).

Foi em parte para responder a esse tipo de crítica que a África do Sul integrou as faculdades de professores na educação superior geral, mudou para uma abordagem de currículo centrada nos "resultados" e pôs a eficiência em sala de aula no cerne das exigências.

O mesmo não ocorreu em outros países. Muitos currículos, quer sejam regulamentados por órgãos do governo ou por autoridades universitárias, continuam organizados em torno da idéia tradicional de "disciplinas" de educação e de conhecimento da matéria ensinada. Estas costumam ser ensinadas separadamente e sem referência à pedagogia dentro da qual a tarefa do professor deveria ser desempenhada.

O quinto problema é que, onde existem cursos de aperfeiçoamento da qualificação, estes costumam enfocar unicamente as "necessidades individuais de qualificação dos professores" sem se preocupar com o impacto que esses processos de aprimoramento poderiam ter sobre seus colegas imediatos ou sobre a escola como um todo. Em algumas escolas, nem os colegas do professor, nem o próprio diretor têm consciência de que o professor está fazendo um curso de aprimoramento. De fato, em dados contextos, o conteúdo do curso de aprimoramento não exige que práticas ou experimentações sejam realizadas na escola em que o professor trabalha.

A sexta e última preocupação política é a inabilidade em desenvolver programas em grande escala. Enquanto o principal modo de pensamento continua sendo uma formação inicial desenvolvida num campus, as possibilidades de passar para programas em grande escala são limitadas. É por este motivo que muitos países estão revisitando as idéias de aprendizado aberto e a distância. A educação a distância e a educação dos professores estão estreitamente vinculadas e, em alguns países, têm uma longa história, mesmo se a imagem da primeira é tradicionalmente problemática (Lewin, 2002), já que costuma ser vista como uma ameaça aos provedores de educação existentes. Mesmo assim, uma característica positiva da educação a distância é ser ela potencialmente capaz de funcionar em grande escala e algumas avaliações indicam sua eficiência onde ela inclui certas variáveis-chave de estrutura de programa. 
Novas tecnologias da comunicação e novos modos de educação a distância

Esta análise aponta claramente para a necessidade de repensar as estruturas e os processos da educação dos professores. As formas de educação dos professores que emergiram no século Xx, em faculdades e departamentos universitários de educação localizados em campi, serão incapazes de atender a demanda deste século. Em muitas partes do mundo, a falta aguda de professores exige que adultos leigos entrem diretamente em sala de aula. Mesmo nas economias mais ricas existem grandes dificuldades. Já mencionamos o grande número de professores leigos no sistema de ensino fundamental estadual californiano. Nos EUA, estima-se (ver Ingersoll, 1999 e 2004) que um terço de todas as aulas de $7^{\mathrm{a}}$ e $8^{\mathrm{a}}$ séries e do ensino médio (grade 7-12) é ministrado por não-especialistas. Em algumas matérias, essa percentagem é mais alta, como em história e ciência, onde metade das aulas é ministrada por não-especialistas.

Portanto, o contexto contemporâneo de professores aponta para uma necessidade de formas de desenvolvimento mais abrangentes de educação e formação centradas na escola. A maior parte do desenvolvimento profissional da maioria de professores terá de ocorrer "no local de trabalho". O velho modelo de formação dada num campus e seguida por licenças para "cursos" de um dia ou mais não pode atender às demandas atuais. E, nesse contexto, a lógica aponta para alguma forma sustentada de aprendizado aberto e a distância.

Tradicionalmente, a educação a distância sempre foi algo como a melhor segunda opção. $\mathrm{O}$ modo de aprendizado daqueles que não poderiam aspirar às universidades de status mais alto. Nelson Mandela obteve um diploma graças à educação a distância, porque estava preso. $\mathrm{E}$ isso continua sendo um problema, particularmente entre os formuladores de políticas ou tomadores de decisões, os quais, provavelmente, seguiram um caminho de educação superior tradicional.

Mesmo com as mais recentes tecnologias da comunicação, que tem um status elevado, o aprendizado aberto e a distância costuma ser visto como segunda melhor escolha (Moon, 2000). O argumento central deste artigo é que essa percepção precisa mudar. Essa mudança é necessária não apenas porque, em muitos setores, existem poucas 
O papel das novas tecnologias da comunicação e da educação a distância...

alternativas, mas também porque, em termos de qualidade, eficiência e sustentabilidade, as novas formas de programas abertos e a distância têm uma melhor relação custo-benefício do que outras alternativas, mesmo tradicionais.

O fato é que o status e a imagem do aprendizado aberto e a distância estão mudando devagar. As novas tecnologias da comunicação forneceram modos criativos e motivadores de apresentar informaçōes e fornecer oportunidades de interação (Leach \& Moon, 2002). A mobilidade crescente dessas tecnologias está abrindo possibilidades, antes impensáveis, para alunos que moram em lugares afastados, geralmente rurais. Um dos mais fascinantes desenvolvimentos desses últimos anos foi o movimento de conteúdo aberto ou recursos educacionais abertos. Baseados na mesma filosofia que as iniciativas de software de códigos abertos (i.e., Linux), os recursos educacionais abertos são disponíveis livremente para que qualquer um possa usá-los e adaptá-los como bem quiser. O investimento significativo da William \& Flora Hewlett Foundation, inclusive no projeto pioneiro de tornar os recursos de ensino do MIT disponíveis nessa forma, espalhou o interesse por essa filosofia, que adota formas de conhecimentos abertas e livres (que, afinal, foram muitas vezes criadas com verbas públicas), em oposição ao mundo fechado da "propriedade" intelectual. Publicações da Hewlett Foundation (Atkins, et al., 2007), da OCDE (OCDE, 2007) e da União Européia (OICOS, 2007) fornecem relatos recentes desse campo emergente.

Embora os sistemas políticos pareçam custar a responder a essas novas possibilidades, um leque de projetos de pesquisa e desenvolvimento interessantes está surgindo e fornece indicadores rumo a uma oferta mais ampla. A implementação detalhada desses programas pode parecer complexa (Moon et al., 2005), mas seus princípios básicos são facilmente elaborados, como podemos ver na figura a seguir.

Nessa estrutura logística, várias abordagens pedagógicas, modelos de desenvolvimento de recursos e sistemas de garantia de qualidade podem ser estabelecidos. As formas de avaliação e de credenciamento também variarão segundo os programas. As novas tecnologias da comunicação, contudo, oferecem mesmo uma gama muito mais rica de recursos e de oportunidades interativas. A terceira geração de telefones celulares, por exemplo, pode ser usada para toda uma série de recursos multimídia. Esses mesmos dispositivos oferecem oportunidades de debater 
com outros professores e com quem lhes dá apoio, de modo tanto sincrônico quanto assincrônico. Seguem apenas alguns exemplos em contextos muito diferentes.

\section{Figura 1}

Apoio aos professores através de um aprendizado sustentado, aberto e a distância

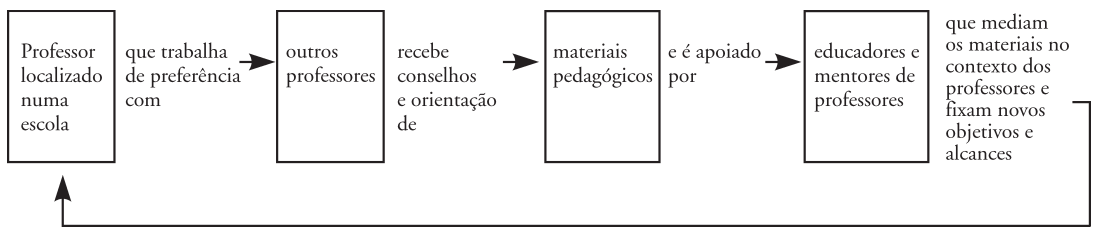

O Programa PGCE (Postgraduate Certificate in Education - Diploma de Pós-Graduação em Educação) de educação inicial dos professores da Open University (Universidade Aberta, Reino Unido)

Esse programa de preparação de professor pelo aprendizado aberto e a distância busca atrair pessoas mais velhas (30 anos e mais) que ingressam no ensino. Uma grande proporção de seus formados supre a falta de professores em matérias como matemática e ciências. Este programa, que existe desde 1994, tem usado conferências assincrônicas desde o início e recorre cada vez mais a estratégias de ensino pela web e on-line (http://www3.open.ac.uk/courses/bin/p12.dll?Q01C21), à medida que as tecnologias evoluem. Hoje em dia, ele oferece caminhos de formação altamente individualizados, inclusive oportunidades mais rápidas para quem tem experiência apropriada.

\section{A iniciativa Enlaces no Chile}

No programa Enlaces (www.enlaces.cl), a formação dos professores dura dois anos. Sua meta é ajudar educadores a incorporar as tecnologias de informação educacionais em seu ensino. Os professores aprendem a usar e-mail, a internet, software educativos e de produtividade em seu trabalho e a lançar mão das tecnologias da informação 
O papel das novas tecnologias da comunicação e da educação a distância...

para criar materiais de ensino. Também aprendem a usar essas tecnologias para tarefas administrativas, como controlar a presença dos alunos e fazer gráficos de notas e planos de aulas. Além disso, adquirem habilidades básicas para trabalhar com esses equipamentos e fazer sua manutenção e para selecionar, adquirir e instalar software educativos.

Depois do segundo ano de formação, oferece-se aos professores um programa de acompanhamento e assistência técnica por um ano, o qual pode ser estendido, caso necessário. Isso permite que as escolas continuem a incorporar ativamente as tecnologias educativas em seus projetos educacionais e desenvolvam uma maior autonomia nessa área.

Em cada escola, um ou mais professores são especialmente treinados para servir de coordenadores Enlaces. Estes supervisionam o uso apropriado das TIC e ajudam alunos e professores a fazer um uso educativo optimal destas. Enlaces, que começou em 1992, já formou milhares de professores primários e secundários.

\section{CalStateTEACH, Califórnia (Estados Unidos)}

O estado da Califórnia lançou esse novo programa de aprendizado aberto e a distância em 1999, em resposta ao crescente número de professores leigos contratados no sistema de ensino fundamental. CalStateTEACH é um programa não-tradicional que oferece tanto um ensino para estudantes, quanto um programa interno para candidatos qualificados interessados em obter seu diploma sem freqüentar as aulas em universitárias tradicionais, já que o currículo é entregue online.

Os participantes usam materiais impressos, em CD-ROM e na web. Compartilham idéias por meio de "discussões de classes" desenvolvidas na web e obtêm um retorno profissional por meio de um acompanhamento no seu local de trabalho. Os participantes do CalStateTEACH também desfrutam da orientação pessoal de professores mentores em sua escola, assim como na faculdade da Universidade do Estado da Califórnia. Comunicam e compartilham suas idéias com outros participantes por meio de um site especial (www.calstateteach.net). 
O programa de recursos educacionais abertos da Teacher Education in Sub-Saharan Africa (Educação dos Professores na África subsaariana TESSA)

TESSA (www.tessafrica.net) é o maior programa cooperativo de educação dos professores na África. Compreende 18 núcleos institucionais membros espalhados em nove países. Meio milhão de professores tem usado materiais da TESSA em 2008, seu primeiro ano de funcionamento. O programa oferece um vasto leque de materiais para apoiar os programas de educação nas escolas dos professores do ensino fundamental. Todos os materiais (tanto escritos como gravados em áudio) são recursos de educação abertos que podem ser usados e adaptados livremente. No momento, esses materiais existem em cinco línguas. Entre seus usuários estão o National Teachers Institute (Instituto Nacional de Professores), na Nigéria, e a Open University (Universidade Aberta), no Sudão, que têm iniciativas de promoção de professores com mais de 100 mil profissionais excedentes.

Vários outros exemplos poderiam ser mencionados. No Brasil, o Ministério da Educação criou um programa de formação inicial que enfoca mais particularmente a necessidade de professores em áreas rurais afastadas. No México, o projeto PRONAP está usando estratégias de aprendizado aberto e a distância desde 1996. Em 2002, um Centro Virtual de Professores foi criado com uma abordagem de workshops on-line. $\mathrm{Na}$ Índia, a Universidade Aberta Indira Gandhi (IGNOU) desenvolveu um curso de habilitação em ensino fundamental destinado especificamente para os 175 mil professores leigos das regiōes siques e dos estados montanhosos do Nordeste, e o rádio e a televisão estão entre seus componentes mais importantes. $\mathrm{Na}$ China, onde o uso de educação a distância para a educação dos professores tem uma longa história, vários projetos existem. A região autônoma de Guangxi Zhieang, por exemplo, desenvolveu um programa de educação a distância dirigido aos 40 mil professores de áreas rurais afastadas. Em 2007, o Ministério da Educação desenvolveu um programa de formação, por meio da educação a distância na web, para 10 mil diretores em 100 lugares específicos desse imenso país.

Os dados sobre a avaliação da eficiência desses programas variam muito. O PGCE, da Universidade Aberta do Reino Unido, é monitorado 
O papel das novas tecnologias da comunicação e da educação a distância...

por um serviço de inspeção governamental externo em nível nacional e notas são disponíveis para os diferentes componentes do programa. Esses relatórios e notas estão à disposição do público (www.ofsted.gov.uk/). O programa TESSA desempenha uma série de avaliações que publica no seu site. Nas últimas décadas, muitos estudos compararam a eficiência, e mesmo a rentabilidade, da educação a distância com a da formação desenvolvida num campus (ver, por exemplo, Perraton, 2000; Latchman \& Robinson, 2002). A maioria revela um otimismo cauteloso sobre os benefícios do aprendizado a distância. Poucos, contudo, foram atualizados para levar em conta o surgimento das novas tecnologias da comunicação (uma exceção seria um estudo encomendado pelo Banco Mundial à Universidade Aberta do Reino Unido, que deveria ser publicado logo, sobre os custos da educação dos professores em dados países da África subsaariana) (Banks et al., 2008, no prelo).

Este artigo argumenta que, para atender à demanda em grande escala por educação dos professores nas décadas por vir, não existe alternativa senão os modos de formação centrados na escola e apoiados pelo aprendizado aberto e a distância. As suas formas podem variar, mas a abordagem geral, para a maior parte do mundo, parece ser a melhor e única opção disponível. Nesse contexto, os resultados de pesquisa e a experiência de programas como os descritos aqui apontam para um número de pontos para futuros questionamentos e pesquisas, entre os quais:

- Que equilíbrio entre velhas e novas tecnologias é mais apropriado para diferentes tipos de programas?

- Que formas de infra-estrutura são necessárias para incorporar as novas tecnologias, efetivamente?

- Que papel podem desempenhar os recursos educacionais abertos, interativos, com uso de multimídia, nos programas de educação dos professores? (Para ser franco, muito da educação dos professores é chata!).

- Como desenvolver modelos de custos "relação qualidade-preço"?

- Como programas podem autenticamente ter repercussões e impactos nas atividades do professor em sala de aula? 
- Que tipos de apoio de pares, mentores, tutores são mais adaptados para as diferentes formas de programa?

E, finalmente:

- De que preparo os formuladores de políticas precisam para traduzir os novos modos de comunicação e as novas formas de programas no processo de planejamento e implementação?

Existe claramente uma necessidade para pesquisas e avaliaçôes abrangentes, se quisermos que os benefícios potenciais da reforma da educação dos professores sejam percebidos.

\section{Uma arquitetura para o desenvolvimento dos professores}

Não é a primeira vez que mudanças rápidas nas formas de comunicação tiveram um impacto significativo em nossas ambições para o progresso educativo e social. A imprensa, o telégrafo e o telefone já mudaram as concepções do mundo. O fim do século XIX, por exemplo, foi um momento de mudanças rápidas. Não apenas o mundo daquele século estava ficando unido numa rede de aço, fios telegráficos e ideologias de progresso, mas também, e talvez de modo mais expressivo, pela primeira vez na história, números crescentes de pessoas em sociedades do mundo inteiro (sociedades que diferiam muito em termos de estruturas, práticas culturais e experiências históricas) começaram a perceber que sua experiência cotidiana e as condiçôes estruturais dessa experiência estavam se afastando. Foi no século XIX que, pela primeira vez, o eu e a sociedade começaram a ser inter-relacionados num meio global, no qual o entendimento que as pessoas tinham de si mesmas e seu sentido do mundo social não poderiam mais ser identificados como exclusivamente ligados a um único lugar, a uma tradição única (Erlmann, 1999). Essas mudanças nas percepções cotidianas de tempo, lugar e identidade foram tão radicais que Robertson (1992) as descreveu como uma "fase de decolagem" da globalização, na qual as "tendências globalizantes" das épocas anteriores foram substituídas por "uma forma única e inexorável”. Em campo, contudo, Erlmann (1999) sugeriu que a emergência de uma concepção singular de alguma coisa chamada humanidade e de um mundo cada vez mais interligado estava além do entendimento conceitual de quem vivesse sob seu domínio. $\mathrm{Na}$ imaginação dos indivíduos, 
O papel das novas tecnologias da comunicação e da educação a distância...

independentemente de onde se encontrassem, esse "sistema global" revestiu-se de um imenso leque de formas de significações simbólicas. Surgiu, então, uma nova forma de imaginação socioespacial que se inscreveu na própria sintaxe da linguagem, as "interseções da ausência e da presença” como Giddens (1991) a chamou.

Nesses novos espaços, criados por rápidas mudanças tecnológicas, surgiram, nos termos de Pierre Bourdieu, "novos intermediários culturais" e novos papéis para intelectuais e artistas. Este é um processo que também está caracterizando, hoje em dia, a nova revolução nas comunicaçôes. As novas formas de tecnologias e a nossa capacidade de reconceitualizar as exclusões tradicionais e as novas práticas, por sua vez, oferecem uma oportunidade de pensar em caminhos novos e mais realistas para o que é humanamente possível. Neste artigo, algumas proposiçôes foram feitas:

- o desafio mundial de expandir as oportunidades educativas tem o desafio concomitante de prover professores e educação dos professores para tornar a experiência da escolaridade significativa e produtiva;

- existe uma necessidade de construir novas formas da educação dos professores, flexíveis e eficientes, centradas na escola, num alcance jamais imaginado até então;

- para tanto, os modelos emergentes de desenvolvimento que exploram novas formas de tecnologia precisam ser examinados para que novas práticas de educação dos professores possam ser compartilhadas, experimentadas e avaliadas mundialmente.

No mundo inteiro, muitas instituições e grupos internacionalmente reconhecidos impulsionam a melhoria da educação dos professores, atraindo acadêmicos e idéias de todas as partes do globo. Poucos, contudo, estão localizados no mundo em desenvolvimento. Poucos são guiados pelas agendas reais dos pobres e dos desfavorecidos. Nossa proposição, aqui, é que a tarefa da educação dos professores consiste em criar uma "arquitetura" nova e imaginativa para um discurso e um debate que sejam verdadeiramente internacionais, lançando mão de práticas e escolaridade de grande alcance, e que abracem o desafio colocado neste artigo. A forma dessa arquitetura, os papéis dos indivíduos 
para criá-la e, juntos, nela trabalhar, assim como o das suas muitas comunidades globais e diversamente relacionadas, constituem uma agenda para o próximo estágio de desenvolvimento.

Recebido e aprovado em agosto de 2008.

Referências

ATKINS, D.E.; BROWN, J.E.; HAMMOND, A.L. A Review of the Open Educational Resources (OER) movement: achievement, challenges and new opportunities. Report to the William and Flora Hewlett Foundation, 2007.

BANKS, F. et al. Title of CAPSAA Project - will put in. Washington, DC: The World Bank, 2008 (forthcoming).

BENNETT, P. Teacher mortality in Sub-Saharan Africa: an update, knowledge and skills for development. Brighton, 2005.

BOLER, T. Approaches to examining the impact of HIV/AIDS on teachers. Policy and Research Series/Save the Children and Action Aid International, 2003.

COLClOUGH, C. et al. Achieving Schooling for All in Africa. Ashbourne: Ashgate Press, 2003.

COMMISSION For Africa. Our Common Interest, 2005. Available at: <www.commissionforafrica.org>

DEMBÉLÉ, M.; MIARO II, B.-R. Pedagogical renewal and teacher development in Sub-Saharan Africa: a thematic synthesis. Association for the Development of Education in Africa Biennial Meeting, 2003.

DLADLA, N.; MOON, B. Why teachers matter: the challenge of teacher supply and teacher development in Sub-Saharan Africa. Symposium presentation to the American Educational Research Association annual conference, San Francisco, April 2006.

ERLMANN, V. Music, modernity and the global imagination. Oxford: Oxford University Press, 1999. 
O papel das novas tecnologias da comunicação e da educação a distância...

GANDHI KINGDON, G. The progress of school education in India. Oxford Review of Economic Policy, Oxford, v. 23, n. 2, p. 168-195, 2007.

GIDDENS, A. Modernity and self identity: self and society in the late Modern Age. Cambridge: Cambridge Review of Books, 1991.

GLOBAL Campaign for Education Teachers for All: what governments and donors should do, 2006.

GLOBAL Campaign for Education/Action Aid. Contradicting Commitments: how the Achievement of EFA is being undermined by the IMF. London Action Aid, 2005.

INGERSOLL, R.I. The problem of underqualified teachers in American secondary schools. Educational Researcher, n. 28, p. 26-37, 1999.

INGERSOLL, R.I. Four myths about America's teacher quality problem. In: Smylie, M.A.; Miretsky, D. (Ed.). Developing the teacher workforce. Chicago: University of Chicago Press, 2004.

LATCHAM, C.; ROBINSON, B. Teacher education through open and distance learning. London: Routledge, 2002.

LEACH, J.; MOON, B. Globalisation, digital societies and school reform: realising the potential of new technologies to enhance the knowledge, understanding and dignity of teachers. 2nd European Conference on Information Technologies in Education and Citizenship: a critical insight. Barcelona, 2002.

LEWIN, K.M. The costs of supply and demand for teacher education dilemmas for development. International Journal of Educational Development, v. 22, n. 3-4, p. 221-42, 2002.

MACDONALD, D. Teacher attrition: a review of literature. Teaching and Teacher Education, v. 15, n. 8, p. 835-848, 1999.

MCGREAL, C. Young teachers are dying, The Guardian, p. 5, 20 dec. 2005.

MELANEY, P. The impact of HIV/AIDS on the education sector in Southern Africa. CAER II Discussion Paper n. 81. Cambridge, MA: Harvard Institute for International Development, 2000. 
MHANDO, E. A not on teacher status in Tanzania. First meeting of the national co-ordinators of UNESCO's Teaching Training Initiative for Sub-Saharan Africa. Paris: UnESCO, 2006.

MOON, B. The Open Learning Environment: a new paradigm for international developments in teacher education. In: MoON, B.; BEN Peretz, M.; Brown, S (Ed.). Routledge International Companion to Education. London: Routledge, 2000.

MOON, B.; VLASCEANU, L.; BURROWS, L.C. Institutional approaches to teacher education within higher education in Europe: current models and new developments. Bucharest: UNESCO, 2003.

MOON, B.; LEACH, J.; STEVENS, M. Designing open and distance learning for teacher education in Sub-Saharan Africa: a toolkit for educators and planners. Washington, DC: The World Bank, 2005.

MORRIS, P.; WILLIAMSON, J. Teacher education in the Asia-Pacific region. A comparative study. New York; London: Falmer Press, 2000.

NELSON Mandela Foundation. Emerging voices. Cape Town: HSRC Press, 2004.

NILSSON, P. Education for All: teacher demand and supply in Africa. Education International Working Papers, n. 12, 2003.

OECD. Giving knowledge for free: the emergence of open educational resources. Paris: OECD, 2007.

OICOS. Open Educational Practices and Resources: Olcos Roadmap 2012, 2007.

PERRATON, H. Open and distance learning in the developing world. London: Routledge, 2000.

REMY, J.P. Des préservatifs de tres mauvaisses qualité modes L'Afrique de L'Est Le Monde, p. 1, 15 Juin 2002.

ROBERTSON, R. Globalisation: social theory and global culture. London: Sage, 1992.

TRANSPARENCY INTERNATIONAL. Global Corruption Report 2006. London: Pluto Press, 2006. Available at: <www.transparency.org>. 
O papel das novas tecnologias da comunicação e da educação a distância...

UNESCO Statistical Document: Education for All 2000 Assessment. Paris: UNESCO, 2000.

UNESCO. Education for All: the quality imperative. Paris: UNESCO, 2005.

UNESCO. Education for All by 2015. Will we make it?. Paris: UNESCO, 2008.

VILLEGAR-REIMER. Teacher professional development: a review of the literature. Paris: UNESCO, 2001. 